\title{
Use of seabirds to monitor sea-surface temperatures and to validate satellite remote-sensing measurements in the Southern Ocean
}

\author{
Henri Weimerskirch ${ }^{1}$, Rory P. Wilson ${ }^{2}$, Christophe Guinet ${ }^{1}$, Malik Koudil ${ }^{3}$

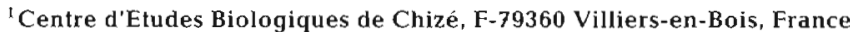 \\ ${ }^{2}$ Institut für Meereskunde, Düsternbrooker Weg 20, D-24105 Kiel, Germany \\ ${ }^{3}$ Centre d'Océanologie de Marseille, Campus de Luminy, Case 901, F-13288 Marseille Cédex 9, France
}

\begin{abstract}
Changes in sea-surface temperature (SST) including the position of the sub-tropical convergence of the southern Indian Ocean were ascertained by using wandering albatrosses Diomedea exulans fitted with temperature recorders and by satellite tracking systems. Flight phases interspaced with frequent pauses on the sea means that albatrosses make useful tools for studying SST in the Southern Ocean, because in situ measurements (to validate satellite data) are rare because of the remoteness of the area. Comparison of satellite-derived data and measurements using albatrosses indicates a good relationship between the 2 sets of data. It is suggested that albatrosses could be useful for monitoring SST and validating satellite-derived data in remote areas of the Southern Ocean, particularly in winter when cloud cover precludes satellite measurements of SST
\end{abstract}

KEY WORDS: Sea-surface temperatures · Bio-monitoring Seabirds $\cdot$ Southern Ocean

The use of seabirds as monitors of environmental change has recently attracted much attention (Furness \& Greenwood 1993). Long-term studies of seabird populations have been used to relate breeding performances of some seabird species to changes in local food availability or to large scale oceanographic phenomena such as the El Niño Southern Oscillation (Croxall et al. 1988, Chastel et al. 1993). More recently, the use of miniaturised data loggers deployed on seabirds indicated that seabirds can be used as cheap platforms to measure oceanographic parameters (e.g Wilson et al. 1994). The measurement of sea-surface temperature (SST) is considered of paramount importance in assessing and documenting the effects of global warming (Jones et al. 1986). Much of the world's oceanic water occurs in the southern hemisphere where measurement is problematic: shipping is infrequent and hazardous, and monitoring by satellite is hindered by extensive cloud cover and atmospheric correction difficulties (Robinson 1985, Rees 1990). In addition, satellites only measure the temperature of the upper 1 to $2 \mathrm{~mm}$ of the water column, which may differ considerably from that within the first $100 \mathrm{~mm}$ of the surface (Robinson et al. 1990).

The aim of this study was to use a large and farranging seabird, the wandering albatross Diomedea exulans, fitted with temperature sensors and satellite telemetry transmitters, to see whether (1) it is possible to measure SST on a large scale in a remote area of the Southern Ocean, (2) such a technique could be used as an accurate alternative to conventional methodologies and (3) it can be used to validate satellite data.

Methods. In situ measures of SST using birds: The study was carried out from Possession Island $\left(46^{\circ} \mathrm{S}\right.$, $52^{\circ} \mathrm{E}$ ), Crozet Islands, southwestern Indian Ocean, between 4 February and 7 March 1994. Five albatrosses were simultaneously fitted with (1) a satellite transmitter that allowed the precise location of the bird during its foraging trip, and (2) a temperature recorder that allowed measurement of the sea temperature (see Table 1). The birds were fitted just after an incubation shift before they left for a foraging trip at sea. Satellite transmitters consisted of Toyocom PTT-T2038 transmitters weighing $98 \mathrm{~g}$, which represents ca $1 \%$ of the mass of a wandering albatross. Units were attached by taping them to feathers in the centre of the birds' backs. The pulse rate of the PTT was $60 \mathrm{~s}$. Temperature recorders consisted of a 128 kbyte archival unit (Driesen \& Kern GmbH, Bad Bramsted, Germany) set to record temperature every $16 \mathrm{~s}$ with a precision of $0.1^{\circ} \mathrm{C}$. The accuracy of the recorder was checked in the laboratory in a water bath before and after deployment in the field. Maximum dimensions of the tube were 
$70 \mathrm{~mm}$ long $\times 18 \mathrm{~mm}$ diameter with a mass of $35 \mathrm{~g}$. Temperature recorders were taped to plastic rings put on the tarsus of the bird. When birds alight on the sea surface, their legs are in the water, so the loggers recorded SST at a depth of ca $100 \mathrm{~mm}$. Temperatures when birds were sitting on the water were easily distinguished from temperatures when birds were flying because they were extremely stable and delimited by a sharp change in temperature as the bird moved from one medium to another (Wilson et al. in press). Water temperature was only considered valid after birds had been on the surface for longer than $120 \mathrm{~s}$.

Times when the birds were resting on the water which coincided with a satellite fix were compiled in a file of all such data to create a matrix of 216 SSTs in relation to position.

SST measured by satellites: Satellite SST data were obtained for 2 consecutive periods ( 1 to 8 and 9 to 16 February 1994) while birds were at sea. These data were collected by the National Environmental Satellite Data and Information Service of the National Oceanic and Atmospheric Administration (NOAA, USA). The temperature measurements were issued from the AVHRR/2 captor (Advanced Very High Resolution Radiometer) of the satellite NOAA 11 with an $8 \times 8 \mathrm{~km}$ coverage. Measurements were made every day by the satellite over an $8 \mathrm{~d}$ period. However SST data could not be obtained when there was cloud cover.

SST maps: Maps of SST were drawn using 2 methods. As a first crude estimate, a map with SST isolines was drawn from temperatures measured by albatrosses using Surfer Golden software for the whole period. This program creates a regular matrix of temperatures from irregularly spaced data. In this manner a large-scale map was produced for a sector located at 30 to $100^{\circ} \mathrm{E}$ and 30 to $50^{\circ} \mathrm{S}$. As in situ measures were particularly abundant in the sector 42 to $47^{\circ} \mathrm{E}$ and 38 to $45^{\circ} \mathrm{S}$, more detailed maps were drawn. SST isopleths were established by the linear interpolation using SAS software and then the representation was obtained by using MIDAS software (Munich Image Data Analysis System) drawn from (1) temperatures measured by albatrosses and (2) temperatures measured by satellite imagery for the period 1 to 16 February. The small-scale albatross map was obtained by interpolating the SST measurements obtained by satellite-tracked albatrosses and the small-scale satellite map by interpolating the SST measured by satellite. The 2 smallscale maps obtained after interpolation were composed of 3620 pixels ( $8 \times 8 \mathrm{~km}$ each).

Comparison between albatross and satellite data: Albatross and satellite data were compared in 2 ways. SST measured by albatrosses at points located by satellite telemetry were related to SST estimated by satellite for the same location at the same time for the periods 1 to 8 and 9 to 16 February. For the sector 42 to $47^{\circ} \mathrm{E}, 38$ to $45^{\circ} \mathrm{S}$, where albatross measurements were at the greatest density, the 2 sets of pixels obtained from the interpolation were correlated to compare the maps obtained for satellite and albatross measurements.

Results. SST as measured by birds: Birds fitted with leg recorders travelled a total minimum distance of $30460 \mathrm{~km}$ (Fig. 1) over 80 bird days, pausing on the water's surface an average of 6 times per day (SD 1.3). A total of 216 SST measurements could be ascribed to positions (Table 1, Fig. 1). Fig. 2 shows part of the temperatures recorded by a single bird ' $E$ ' on its travel to the north of Crozet, up to $30^{\circ} \mathrm{S}$ latitude. Just after leaving its nest, the bird alighted on water off Crozet, where the SST measured was $7.6^{\circ} \mathrm{C}$. The bird then moved to the north of Crozet, settling on the water several times, and recording increasing SST. The bird reached sub-tropical waters at a latitude of $30^{\circ} \mathrm{S}$ where SST peaked at $23.5^{\circ} \mathrm{C}$. The albatross then

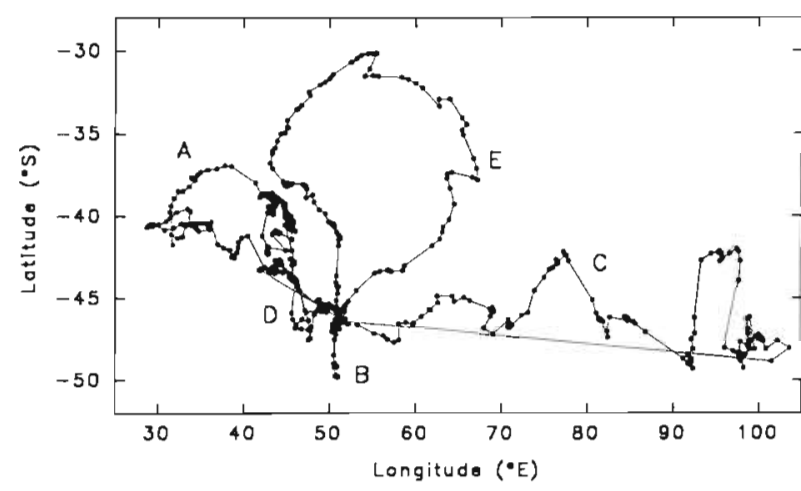

Fig. 1. Tracks of 5 wandering albatrosses Diomedea exulans fitted with satellite transmitters and temperature recorders to their legs. Each dot represents a fix where SST was measured by the bird

Table 1. Duration of the simultaneous deployment of satellite transmitter and temperature loggers as well as the number of satellite fixes and number of SST measured by 5 wandering albatrosses Diomedea exulans in 1994

\begin{tabular}{|ccccc|}
\hline Track & $\begin{array}{c}\text { Sex of } \\
\text { birds }\end{array}$ & $\begin{array}{c}\text { Time of } \\
\text { deployment }\end{array}$ & $\begin{array}{c}\text { No. of satellite } \\
\text { fixes }\end{array}$ & $\begin{array}{c}\text { No. of SST } \\
\text { measurements }\end{array}$ \\
\hline A & $F$ & $4-24$ Feb & 187 & 54 \\
B & M & $7-12$ Feb & 51 & 19 \\
C & M & $5-17$ Feb & 129 & 64 \\
D & F & $6-16$ Feb & 128 & 35 \\
E & F & 22 Feb-8 Mar & 127 & 44 \\
\hline
\end{tabular}


Fig. 2. Temperatures recorded by the female albatross ' $E$ ' that moved in a looping course from Crozet to subtropical waters at $30^{\circ} \mathrm{S}$ before returning to its nest. Stable temperatures correspond to SST when the bird is sitting on the surface with its legs, and the recorder, under water. When the bird is flying, temperatures fluctuate, and are generally higher than $25^{\circ} \mathrm{C}$ because the bird tucks its legs into its plumage. The values under stable recordings indicate the SST measured by the bird

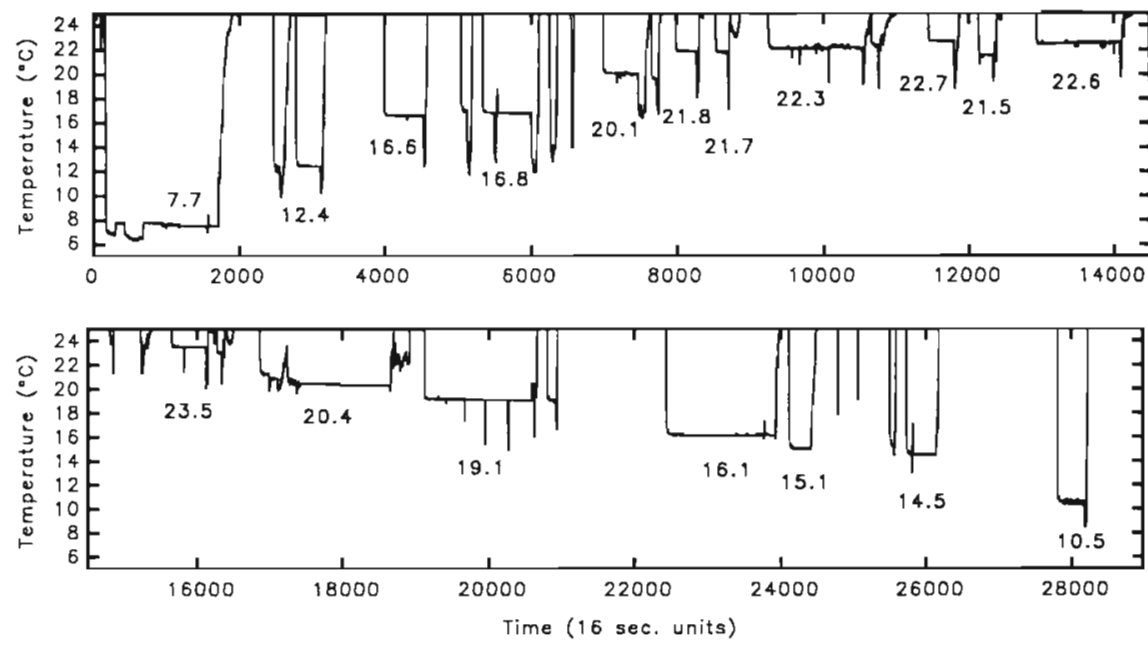

returned to Crozet recording decreasing SST on its way back to the nest.

The reconstructed map indicated that SST decreased from $23^{\circ} \mathrm{C}$ at latitudes of $32^{\circ} \mathrm{S}$ to temperatures of $15^{\circ} \mathrm{C}$ at about $42^{\circ} \mathrm{S}$, decreasing further steadily to $5^{\circ} \mathrm{C}$ at $50^{\circ} \mathrm{S}$ (Fig. 3). The narrowing of the isopleths around $42^{\circ} \mathrm{S}$ corresponds to the sub-tropical convergence that appeared to be well defined between 40 and $70^{\circ} \mathrm{E}$, but became less compact and occurred further southeast of $70^{\circ} \mathrm{E}$ (Fig. 3).

Validation of satellite measures: There was a significant relationship between SST measured by albatrosses and SST obtained by satellite measurements for the same location over the two $8 \mathrm{~d}$ periods $\left(\mathrm{SST}_{\mathrm{Sat}}=\right.$ $1.021 \pm 0.0143 \mathrm{SST}_{\mathrm{Alb}}-0.270, \mathrm{r}^{2}=0.969, \mathrm{n}=166, \mathrm{p}<$ 0.001; Fig. 4).

The 2 maps obtained by the interpolation of the satellite SST and the albatross SST presented the same general distribution of the SST. They allowed the location of the sharp temperature gradient associated with the Sub-Antarctic/Sub-tropical Transition Frontal
Zone, whereby SST isopleths, interpolated using comparable techniques from albatross SST and from satellite SST, appear similar (Fig. 5). Comparison of the 2 pictures using linear regression presented a highly significant relationship between the set of SST of the 2 interpolated pictures, each being composed of 3620 pixels $\left(\mathrm{SST}_{\text {Sat }}=1.0381 \pm 0.0039 \mathrm{SST}_{\text {Alb }}-0.289, \mathrm{r}^{2}=\right.$ $0.95, \mathrm{p}<0.0001, \mathrm{n}=3620$ ).

Discussion. The results of this study show that it is possible to use large seabirds as cheap platforms to measure SST on a large scale using new technologies. From these measurements it is possible to draw SST maps accurately, depending on the number of individuals that have been used. The utility of animals as monitors of the environment (Furness \& Greenwood 1993) depends on our ability to define the areas in which they forage. Satellite-tracking studies accurately pinpoint the movements of wandering albatrosses. These birds are large and capable of carrying sophisticated measuring apparatus remarkable distances over some of the earth's most intractable surface

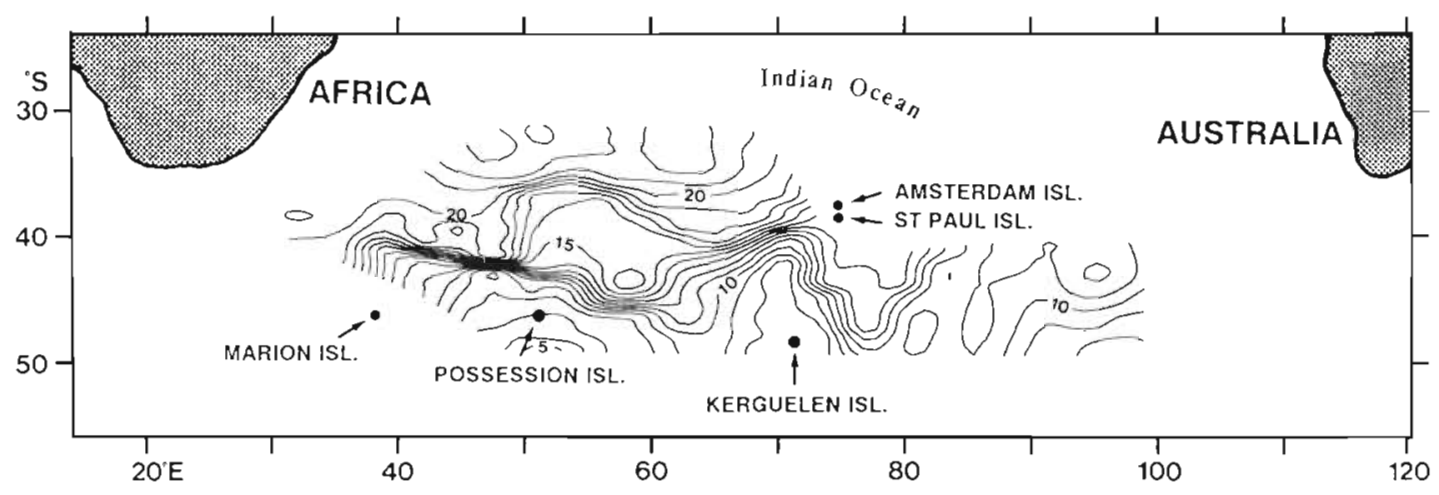

Fig. 3. SST depicted by $1^{\circ} \mathrm{C}$ isotherms (measured at a depth of ca $100 \mathrm{~mm}$ ) as measured by 5 albatrosses breeding at Possession Island, southern Indian Ocean 


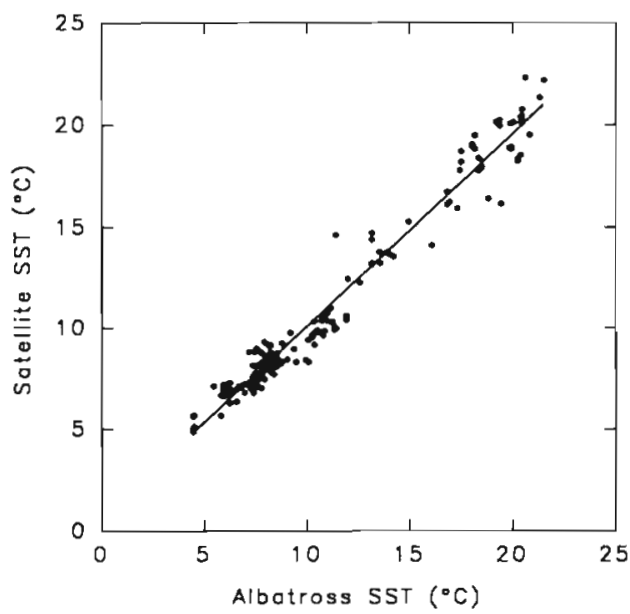

Fig. 4. Correlation between SST as measured by albatrosses and as estimated from satellite imagery

before returning days later to their nests where units can be easily retrieved. Wandering albatrosses are seabirds foraging over wide areas. Crozet birds forage over an area of 32 million $\mathrm{km}^{2}$ in the southern Indian Ocean, in an area bounded by 25 and $66^{\circ} \mathrm{S}$, and $10^{\circ} \mathrm{W}$ and $100^{\circ} \mathrm{E}$ (Jouventin \& Weimerskirch 1990 , Weimerskirch et al. 1993, unpubl.). These birds are consequently excellent for assessments of SST over an extensive range. Given the foraging range of wandering albatrosses and the fact that their breeding season occurs over the entire year, the whole of the Southern Ocean could be monitored by birds nesting at just 3 localities: Possession Island, South Georgia $\left(54^{\circ} \mathrm{S}, 37^{\circ}\right.$ $\mathrm{W})$ and Auckland Island $\left(51^{\circ} \mathrm{S}, 166^{\circ} \mathrm{W}\right)$.
ALBATROSS

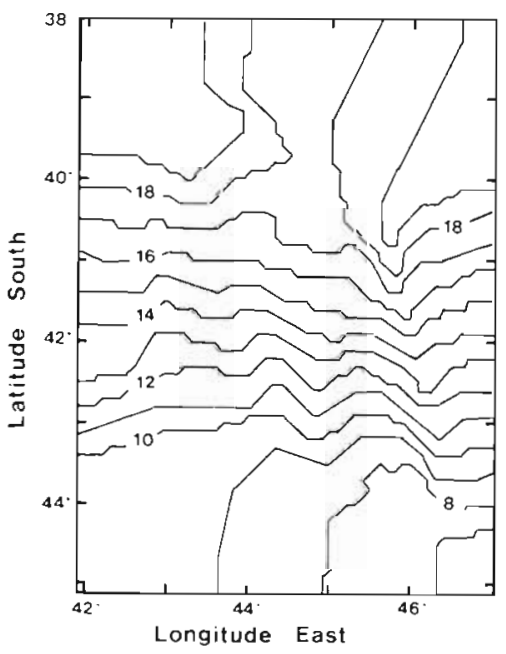

SATELLITE

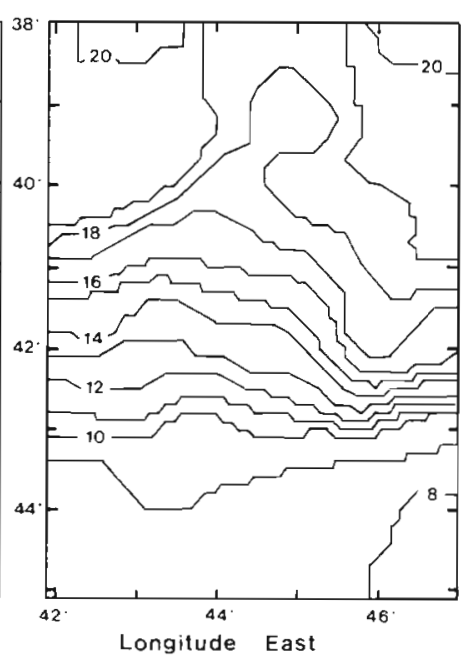

Fig. 5. Maps of SST isopleths deduced by the same technique from albatross data and from satellite data for 1 to 16 February 1994
This technique appears to be a useful complement to the remote-sensing measurement of SST by satellite as in situ measurements can be obtained in locations where very few such measures are obtained by conventional oceanographic ships. Brown (1990) emphasised the need for in situ measurements in the southern latitudes for the parametrization of theoretical modelling. Furthermore the data obtained by the AVHRR of the NOAA satellite allows the reconstruction of SST with a precision of between 0.5 and $2^{\circ} \mathrm{C}$, according to the model used. The present study shows a very good agreement of the SST obtained by 2 systems and we can be confident in the SST maps obtained in this study. The differences between the 2 measurements could be related to the fact that albatrosses are measuring temperatures at a depth of $100 \mathrm{~mm}$ while satellite sensor measurements are restricted to 1 to $2 \mathrm{~mm}$.

Small-scale albatross and satellite maps appear comparable, and the correlation between the values derived from the 2 maps is highly significant. The difference in the isolines of albatross and satellite SST maps is the result of the relatively small number of measures made by albatrosses in this sector. This problem is emphasised in the larger map derived from albatross data. This indicated that SST maps obtained through interpolation of SST available within an area can only by precise if a sufficient density of SST measurements randomly distributed over a defined area are available. However, to obtain a minimum density of SST measurements the number of birds fitted with data recorders should be higher than for this study. The use of seabirds to obtain SST on a large scale in remote areas would be particularly appropriate during the southern winter when cloud cover is almost permanent, almost precluding measurement by satellite. At this time of the year wandering albatrosses range extensive distances from their breeding grounds (Weimerskirch et al. 1993), allowing extensive coverage of the Southern Ocean if a significant number of birds is used. Because birds forage from a central place, coverage near the breeding grounds is better than further away. Our study indicates that even a limited number of birds allows a good coverage of a restricted area, in our case the area of the sub-tropical convergence west of Crozet. As the predicted effects of global warming are not uniform but expected to be greater in limited areas, a very low number of albatrosses fitted with satellite transmitters and temperature sensors would, for example, allow the regional monitoring of frontal zones. 
Acknowledgements. This work was supported by the Institut Français pour la Recherche et la Technologie Polaires, GDR polaire (Bio-monitoring) from CNRS and the Deutsche Forschungsgemeinschaft (grant MZ DFG 24/11). We are grateful to JVC for help with equipment, P. Lys for help in the field and $\mathrm{M}$. Kierspel for helping with data analysis.

\section{LITERATURE CITED}

Brown RA (1990) Meteorology. In: Smith WO (ed) Polar oceanography, Part A, Physical science. Academic Press, San Diego, p $1-46$

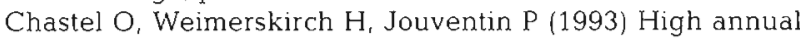
variability in reproductive success and survival of an Antarctic seabird, the snow petrel: a 27 year study. Oecologia 94:278-285

Croxall JP, McCann TS, Prince PA, Rothery P (1988) Reproductive performance of seabirds and seals at South Georgia and Signy Island, South Orkney Islands 1976-1988: implications for Southern Ocean studies. In: Sahrage D (ed) Antarctic Ocean and resources variability.

This note was submitted to the editor
Springer-Verlag, Berlin, p 261-285

Furness RW, Greenwood JJD (1993) Birds as monitors of environmental changes. Chapman \& Hall, London

Jones PD, Wigley TML, Wright PB (1986) Global temperature variation between 1861 and 1984. Nature 322:430-434

Jouventin P, Weimerskirch H (1990) Satellite tracking of wandering albatrosses. Nature 343:746-748

Rees WG (1990) Physical principles of remote sensing. Cambridge University Press, Cambridge

Robinson IS (1985) Methods of satellite oceanography. Ellis Horwood, Chichester

Robinson IS, Wells NC, Charnock H (1990) Oceanography from space. Plenum Press, New York

Weimerskirch $H$, Salamolard $M$, Sarrazin $F$, Jouventin $P$ (1993) Foraging strategy of the wandering albatross through the breeding season: a study using satellite telemetry. Auk 110:325-342

Wilson RP, Culik BM, Bannasch R, Lage J (1994) Monitoring Antarctic environmental variables using penguins. Mar Ecol Prog Ser 106:199-202

Wilson RP, Weimerskirch $\mathrm{H}$, Lys $\mathrm{P}$ (in press) A device for measuring seabird activity at sea. Avian Biol

Manuscript first received: December 13, 1994

Revised version accepted: April 4, 1995 